\title{
How Hotel Industry Copes Up with the COVID-19: An SME Perspective
}

\author{
Muhammad Nawaz Tunio ${ }^{1 *}$, Lenny Yusrini2, Zubair A. Shah ${ }^{3}$, \\ Naveeda Katper ${ }^{4}$, Mushtaque Ali Jariko ${ }^{5}$ \\ 'Greenwich University, Karachi, Pakistan \\ ${ }^{1}$ Alpen Adria University, Klagenfurt, Austria \\ ${ }^{2}$ Akademi Pariwisata Indonesia, Jakarta, Indonesia \\ ${ }^{3}$ Salim Habib University, Karachi, Pakistan \\ 4,5 University of Sindh, Jamshoro, Pakistan

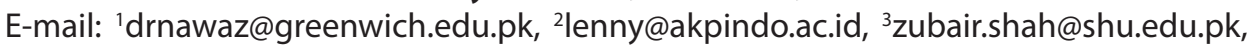 \\ ${ }^{4}$ nksyed@usindh.edu.pk, ${ }^{5}$ mali.jariko@usindh.edu.pk \\ ${ }^{*}$ Corresponding Author
}

JEL Classification:

$\mathrm{B} 17$

B27

F30

L83

Received: 16 January 2021

Revised: 08 May 2021

Accepted: 30 May 2021

\begin{abstract}
This study aims to determine the plans and strategies adopted by the hotel industry during the COVID-19 crisis. In order to conduct this study, a qualitative research methodology was used where semi-structured interviews were conducted from three countries: Austria, Pakistan, and Indonesia. Interviews were conducted online with the help of applications such as Skype, WhatsApp, and Zoom. A thematic analysis was conducted in which codes, categories, and final themes were generated. The final themes are the study's findings, which are strategies for employees, strategies for customers, strategies for SME hotels, and strategies for the staff. Strategies for employees indicate the planning and programs of the SME Hotels. The study's findings show that strategies adopted by the hotel industries vary from country to country while depending on the contextual factors and role of the government. Most Small and Medium Enterprises (SMEs) hotels in developing countries are less familiar with how to react and survive in the conditions of the crises. Thus, this study can benefit the different stakeholders in the developed and developing countries for adopting strategies and maintain their business during the crises of the COVID-19.
\end{abstract}

Keywords:

hotel industry, SMEs, covid-19, strategies

\section{How to Cite:}

Tunio, M. N., Yusrini, L., Shah, Z. A., Katper, N., \& Jariko, M. A. (2021). How Hotel Industry Cope Up With The Covid-19: An SME Perspective. Etikonomi, 20(2), 213 - 224. https://doi.org/10.15408/etk.v20i2.19172. 


\section{Introduction}

The COVID-19 pandemic has forced various short-term and long-term negative impacts on the hotel industry at the international level. The immediate effects have become well evident and reflected in the intruded-on incomes incited by unexpected business terminations following the orders of lockdown imposed by the government. Such sudden closure has imperiled the business life span of numerous hotels by slicing their profits and breaking down the well-established and long supply chain. The long-term effects of COVID-19 are yet confirmed; however, prone to be exemplified by the low demand of the consumers for hospitality services because of wellbeing and hygiene factors and precautions (Filimonau et al., 2020). Research on the hotel industry has received increasing attention after the outbreak of the COVID-19 because this fluctuation has penetrated the hotel industry very badly. It is observed that large and famous hotels like Hilton and its 150 chains were closed in China and were prone to the recession because it was conserved a tourist series. In this situation, small and medium enterprise hotels were more vulnerable (Hao et al., 2020).

Initially, the outbreak of the pandemic was taken for granted against the outbreak of the COVID-19. Visitors still crowded many tourist destinations in Asia and Europe, which provoked the COVID-19 and increased rapidly. With the pandemic spread worldwide, the hotel industry's road to recovery has become much longer, and crisis management strategies need to be adjusted over time. So far, recent studies in crisis management practices only focused on a single point in time (Israeli et al., 2011), and research on epidemic crises was conducted in the post-crisis stage (Lee, 2009; Wan, 2013). This research gap, thus, needs to be filled by having a continuing study in the during-crisis stage to answer the research question of what the hotel industry should undertake crisis management practices at different times during an epidemic outbreak.

The hospitality industry is known to be the source of many job opportunities and support the livelihoods of millions of workers and their families. Although the precise number of jobs is difficult to quantify, some estimates mentioned that the hospitality industry employs more than 212 million people across the globe. For some countries such as the Maldives, Cambodia, Thailand, and Fiji, this industry sector-including travel and tourism- is the primary employment opportunity and contributes to the local, regional, and national economy (Jones \& Comfort, 2020).

History has noted that the tourism and hospitality industry, including the hotel industry, is vulnerable to the crisis brought by unpredicted disasters such as terrorist attacks, epidemics, and natural catastrophes (Hung et al., 2018; Jiang \& Wen, 2020). Various measures were taken by hotel management to strengthen their hotels in facing different attacks of disasters and to address the changing behavior of consumers. COVID -19 "buried" the world in only a matter of weeks. Millions of people's health and lives across the world are at stake. International, and in some countries, domestic tourism as well, have been shut down. The disastrous impacts of COVID-19 have produced temporary, and on some occasions, permanent, loss of jobs in the hospitality industry. The most impacts were felt by the workforces in less developed countries, where it is 
little or no financial support from the governments, no organized trade union protection for workers, and millions of people have been thrown into poverty (Jones \& Comfort, 2020). The COVID-19 pandemic has changed the relationships between the hospitality industry and sustainability (Kim et al., 2021).

Following the COVID-19 pandemic, the tourists' awareness of health risks and security increases, the hoteliers have many things to do to restore their confidence (Jiang $\&$ Wen, 2020). The hotel industry needs to develop innovative technologies to win back the tourists' confidence in the hotels. These technologies should reduce physical contact while still improving operation and service productivity (Rahimizhian \& Irani, 2020). The impacts of COVID-19 did not only change the tourists' perception, behavior, and intention to visit. From the employees' point of view, the perception has changed too. The bitter lesson learned is that employment is not something we can take for granted. The organization's resilience and response to COVID-19 affect the senior managers' perceived job security (Filimonau et al., 2020), thus determining their commitments to the organizations.

In the USA, the federal decisions in dealing with the COVID-19 pandemic were somehow slow. The slowness in responding was due to the defunding of the Office of Pandemics and Emerging Threats. It was also found that there was a lack of coordination between the federal government and the states. This situation contributed to the rank of the USA having the highest COVID-19 infection and fatality rates globally (Schismenos et al., 2020). The COVID-19 pandemic situation has impacted the image of the community and the destination negatively. In India, some hotels display irresponsible behavior towards their guests due to panic and mistrust. This kind of action immediately affected the relationship between the host and the guests. However, they also expected some support from the host during this crisis (Kour et al., 2020).

In Wuhan and Hubei Provinces of China, the workers in tourism and hospitality sectors such as hotels, travel agencies, cruise lines, and tourist attractions found looming uncertainty in the short term. A fast response is called to address these issues. For instance, they are implementing governmental subsidies and managing internal cost control while anticipating long-term actions. Some essential steps such as product adjustments, business structure transformation, and restoring market confidence should be taken (Knight et al., 2020). On the opposite side, the virus outbreak affected Chinese tourists' lifestyles, behavior, and preferences in the short and long term. For the Chinese, the new forms of tourism, such as slow and smart tourism, are likely the Chinese tourists' consumption patterns. Such a shift in popularity will force the hospitality industry to redesign its service and distribution channels. (Wen et al., 2020).

While tourists rethink how they will travel during and after the COVID-19 pandemic, tourism and hospitality practitioners need to reflect on creating better and positive changes to the industry. One actionable strategy to help in alleviating the tourists' stress is enriching the tourists' experience. There are very few studies that pay attention to the hostel industry on coping with the COVID-19 situation in specified countries through a qualitative study. Entrepreneurs in the area of the hotel sector are planning 
and developing strategies to deal with the COVID-19 crisis. Because, initially, it was thought to be a one-time disaster. However, over time and the increasing intensity of the COVID, the second wave was triggered, which indicated more severity and intensity. Besides this, the rise of the mutated virus from the UK has issued more serious warnings. Therefore, an urgent study is needed to fill this research gap.

This article focuses on SME perspectives. An essential objective of this study is to conduct a comparative analysis among three countries, Austria, Pakistan, and Indonesia, to find out how the hotel industry copes with COVID-19. To pursue the objective, semi-structured interviews were conducted from hotels in these three countries. The findings of the study have emerged from the themes, which are presented here. Few latest research work also emphasized and endorsed the effects of the COVID-19 on the hotel industry and their survival from SME perspectives in the crises (Jiang \& Wen, 2020; Gursoy \& Chi, 2020; Baum \& Hai, N.2020; Alonso et al., 2020).

\section{Methods}

In this study, a qualitative approach was used for the data collection, and data was collected through semi-structured interviews. The interview is the common tool of data collection in qualitative research, which provides an opportunity to translate and interpret participants' experiences (Tavory, 2020). Sample size in qualitative research varies according to the research question and scope (Rowley, 2012). Online interviews were conducted from the 12 hotels of the three countries of Austria, Pakistan, and Indonesia (Braun \& Clarke, 2021). These three countries were chosen for the study because the authors live in those countries, and it was easy for the authors to collect the data through the snowball technique (Fofana et al., 2020; Jamshed, 2014).

Table 1. Hotel Industry

\begin{tabular}{|c|c|c|c|c|}
\hline Case & Hotels & Country & State/Province & City \\
\hline \multirow{4}{*}{1.} & Hotel - 1 & \multirow{4}{*}{ Austria } & Carinthia & Villach \\
\hline & Hotel - 2 & & Carinthia & Velden am Wörther See \\
\hline & Hotel - 3 & & Carinthia & Spittal \\
\hline & Hotel - 4 & & Carinthia & Millstatt \\
\hline \multirow{4}{*}{2.} & Hotel - 1 & \multirow{4}{*}{ Pakistan } & Sindh & Larkana \\
\hline & Hotel - 2 & & Sindh & Khairpur \\
\hline & Hotel - 3 & & Sindh & NawabShah \\
\hline & Hotel - 4 & & Sindh & Mirpurkhas \\
\hline \multirow{4}{*}{3.} & Hotel - 1 & \multirow{4}{*}{ Indonesia } & West Java & Cibinong \\
\hline & Hotel - 2 & & West Java & Bogor \\
\hline & Hotel - 3 & & West Java & Citeureup \\
\hline & Hotel - 4 & & West Java & Tambun \\
\hline
\end{tabular}

Source: Data processed by authors

After completing the interviews, transcription of the interviews was developed, transcription was assessed and evaluation of the text carefully, from a large amount of 
the data of the transcription, codes were generated, from the codes, categories were generated, and from the categories, final themes were generated, final themes are the findings of the study (Guest et al., 2020; Im \& Chee, 2006). Thematic analysis is conducted manually because human-read can understand the experiences shared by the participants, and sometimes, the software is unable to interpret in the right way Rowley, 2012). The profile of individual cases is given in Table 1.

\section{Results and Discussion:}

\section{Themes}

The thematic analysis approach is used to analyze the data because the thematic analysis is supportive of the emerging themes from the codes generated from the transcription (Gioia et al., 2013). Qualitative methods have endorsed that thematic analysis conducted manually is more specific, relevant, and informative, translating and interpreting the terminologies, words, and expressions (Braun \& Clarke, 2006).

In the analysis, every case was written down as a story format to observe and analyze entrepreneur views and experiences during COVID-19, which led us to derive the themes. Therefore, to extract themes, we repeatedly read the interview text to familiarize and develop our understanding. The next step was to create a manual coding (Seale and Kelly, 3014) to label and code text patterns. Finally, repeated patterns gave rise to themes. This procedure resulted in four main themes. After the emerging of the themes, these were presented in the tabular presentation to interpret the data (Alhojailan, 2012). Table 2 presents the first codes, categories, and themes of this research.

Table 2 provides information on the thematical analysis process. This analytical table indicates the serial number, list of the codes generated from the transcriptions, and themes consequently. It provides information on the total codes that emerged from a transcription of the interviews and the final findings in the form of final themes.

In the thematic analysis, codes, categories, and themes are generated. Through thematic analysis, four themes emerge in the form of significant findings: strategies for employees, strategies for customers, strategies for SME hotels, and strategies for the staff. Strategies for employees indicate the planning and programs of the SME Hotels. SME exists in different forms in the countries, industries, organizations, and communities around. Numerically, SMEs have 1 to 100 employees, while in some exceptional cases, 250 employees are considered. In this way, small-scale enterprises are considered to have 50 to 100 workforces, and medium-sized enterprises are considered to have 250 workforces (Inyang, 2013). Therefore, SME Hotels are considered on the strength of the workforce (Serrasqueiro \& Nunes, 2014).

\section{Strategy for employees}

This study tried to explore the strategies adopted by SME hotels (Donthu \& Gustafsson, 2020). In the emergency of the COVID-19 pandemic, SMEs in the hospitality sector have played a very responsible role by considering the needs, issues, and concerns. 
Addressing the issues of the staff varies from country to country, depending on the strength of the country's economic status.

Case 1: Austria. "Announcement of the government of the relief to the hotel as well as staff of the hotel, however, responsibilities performed by the hotel management gave us a feeling of safety by all means."

Table 2. Thematic Analysis

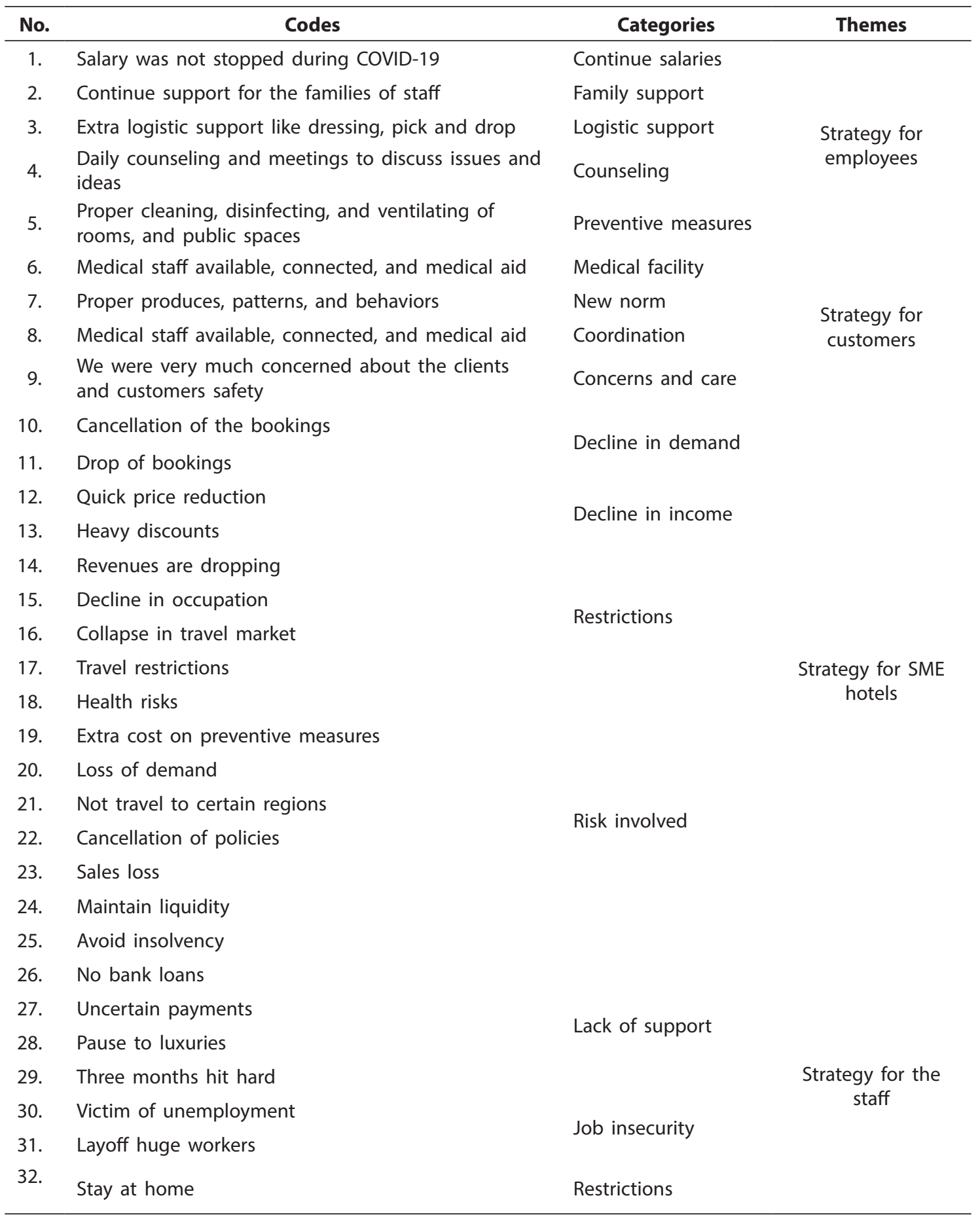

Source: Created by author 
In this condition, it is a very responsible role of the SME hotels to contribute in the supporting, cooperating, and developing of their staff in the developed countries because most of the European countries, including Austria, respective governments declared incentives and financial support to the workers in the different organizations including the SMEs Hotel.

Case 2 Pakistan: "It was very terrible to perform our duties during the pandemic situation, but we appreciate the hotel management taking care of us along with playing social responsibilities."

In the case of the European countries, the management of the SME hotels ensured to extend and continue support for the families of staff in the COVID-19 situation because there were several uncertainties and threats to everyone. However, the situation in developing countries like Pakistan and Indonesia, where the respective governments did not declare any support scheme, was exposed to several challenges.

Case 3 Indonesia: "Initially, the situation of COVID-19 was taken non-seriously. However, people started to believe it when it became a severe issue. Thus, in this situation, the government announced support for the affected people only. However, hotel management was not relying on such support. But provided some marginal support to the staff for the survival and safety of the staff and their families."

Daily counseling and meetings to discuss issues and ideas and educate them about the COVID-19 situation, consequences and preventive measures in the work routine were delivered to the staff to keep them informed about the changed situation. Proper cleaning, disinfecting and ventilating of rooms and public spaces.

\section{Strategy for customers}

This theme focuses on the facilities and support provided by SME hotels. It is mentioned here that the hotel management provided medical aid and medical consultation to the customers whenever required. This theme indicates that SME hotels were very much concerned about the clients' and customers' safety.

Case 1 Austria: "It was our priority to provide all the facilities and the basic immediate aid to the customers and tourists. During their stay, all the customers were provided with the proper orientation and guidance. They were instructed to abide by the rules and preventive measures to follow social distance, use of the marks outside the rooms and hotels and use the sanitizers frequently and wash their hands again and again when they are exposed to the external environment."

This shows that the SME hotels in the developed countries are well equipped with sound infrastructure, environment, and facilities. Therefore, these are in the position to support their customers and consumers. Therefore, these hotels go out of the way to support their customers and make them safe and secure. They provide all medical facilities when required in the COVID-19 and offer them all preventive measures.

Case 2 Pakistan: "We tried out best to facilitate our customers with available facilities and services. However, due to small enterprises with limited resources, we could not do everything possible and provide the standard protocols as compared to internationals". 
On reflection of the above case of Pakistan, it seems developing countries are not in the position to support their customers in the way customers are supported in the developed countries. It means developing countries want to offer all facilities and provide satisfaction to the customers, but their income is not sufficient enough to develop a support system.

Case 3 Indonesia: "During the COVID-19 conditions, there was a lockdown and due to this, all hotels were closed from the functions. Hence, there was no chance to offer or perform CSR practices for the customers".

However, in contracts to the case 1 and 2, case 3 Indonesia, indicates that there was no practice of the CSR for the customers during the COVID-19 situation as there everything was close, travel and transport were stopped, and thus, mobility of the people was paused.

\section{Strategy for SME Hotels}

This theme focuses on the spillover effects of the COVID-19 on the performance of the SME hotels in Austria, Pakistan, and Indonesia. Hence, this theme determines the challenges faced by SME hotels. The challenges were in different forms and in different ways. Theme indicates that the travel restrictions caused a collapse in the hospitality market and caused the cancellation of policies for advance booking in certain regions. People avoided unnecessary travel to avoid the health risks, loss of health, and lose of life.

Case 1 Austria: "Due to the ban on the travel and transportation, mobility of people was limited. Limited travel either for tourism or for business was given a short pause".

However, further, it is indicated that SME hotels experienced the spillover effects of the COVID-19 on the financial condition in different forms and different ways. It was mentioned that revenue was dropping, the sales were decreasing, and expenses were increasing

Case 2 Pakistan: "In the situation of the COVID-19, income was decreasing due to the cancellation of the bookings, extra cost needed on the proper protocols, preventive measures and heavy discounts to the customers"

This shows that COVID-19 created challenges for the SME hotels in both ways, one, by reducing the customers' demand and rapid flow of the people and second, by offering heaving discount and extra care to attract and satisfy the customers.

Case 3 Indonesia: "We need to close the services because it was getting very expensive to earn less and expense high than income. Therefore, being a small enterprise, we cannot bear the cost of CSR"

In this regard, it is mentioned under this theme that SME hotels were losing their revenue, sales bookings, and prices in the emergency situation of the COVID-19. The extra cost of preventive measures increased the economic burden for SME hotels. Besides this, quick price reduction and heavy discounts created serious challenges. 


\section{Strategy for the staff}

This theme mentions the challenges faced by the employee of the SME hotels during the COVID-19 situation.

Case 1 Austria: "It was a stressful situation for me and my colleagues to work and manage, we were worried for our safety as well as performing duties. In such a situation of fear, we were afraid of losing jobs, and there was the refusal of the banks as well for any loan."

This shows that the employee of the SME hotels was highly afraid of losing health, jobs and even life. In this condition, it was very challenging for them to manage work and life balance during the hard hit of the three months.

Case 2 Pakistan: "Fear of losing a job was high and there was stress that who will be refused from the employment by the hotel management. However, it was also very stressful to navigate between hotel and home, and most of the time we needed to stay at either home or hotel in order to avoid being affected"

The above-mentioned statement shows that the employees were under the double stress of the job and fear of being affected. Job fears kept them in the active position to prove their best in the performance so that management may not feel something low regarding their performance, and satisfaction from the service in the developing country of case 2 .

Case 3 Indonesia: "Tension was high due to the shutdown of the hotels and half salary was given which was not sufficient to run home and maintain home expenses. In this situation, we were unable to find any other kind of work, as well as the market, was sinking already from the work or employment opportunities."

The above statement indicates that there were serious challenges faced by the employee of the hotels in developing countries like Indonesia. COVID-19 created issues for the staff in getting low salary or half salary from the hotel where they were working and due to the lockdown situation, they were helpless to find any other kind of work for their survival. Hence, it created a big challenge for the employee of the SME hotels in the developing country.

There is a uniqueness in being small or medium-sized enterprises. When larger enterprises have great assets that will clear up their path in many ways, small and medium-sized ones may lack the necessities in taking advantage in the marketplace (Bögenhold \& Fachinger, 2007). However, many proofs have shown that there were times smaller enterprises were able to defeat the disadvantage of being small and develop at an astounding rate (Hisrich \& Soltanifar, 2021). They surprised the marketplace as the survivors and grew with prosperity (Pett et al., 2019). To do this, the managers of small and medium-sized enterprises (SMEs) need to have strategic innovations to meet the firm's goals. (Haddad et al., 2019) found that some of this success is owed to the top management's role in encouraging an innovative culture (Bögenhold et al., 2021).

To be able to build a firm name in the marketplace, SMEs need to have good branding. SME's brand-building attempts comprise these factors: (1) implementing various approaches in promoting the brand; (2) using the unique yet recognizable brand name; (3) offering different products; and (4) showing product/service offerings by attending exhibitions. 
For a service-based SME, the use of a brand name contributes to the firm's performance. This condition happens because a service-based SME's primary products are intangible. Thus the brand name is automatically woven into the brand name (Odoom et al., 2017).

Open innovations seem to be the keywords for SMEs to have sustainable growth. (Yun et al., 2015) mentioned that a knowledge strategy and business model are the two kinds of open innovation needed. SMEs with limited human resources and resources need to have various resources from external parties rather than forcing themselves to prepare all resources and capabilities. Another innovation required for the sustainable growth of SMEs is the adoption of Information and Communication Technology (ICT).

Interestingly, the paradigm shift in the ICT brings dynamism and complexity to the SME's competition level. Within accessible environments, the ICT capabilities are more distributed in larger SMEs, both internal and external oriented processes. In contrast, medium-sized enterprises tend to develop ICT capabilities internally and fail to manage ICT capabilities for their external environments. How well the ICT is adopted in the firms depends on the environmental influences (Neirotti et al., 2018).

\section{Conclusion}

This study contributes to the contemporary realm of research on COVID-19 to understand how SME hotels respond to the pandemic situation in Austria, Pakistan, and Indonesia and what strategies were implemented by these while working in this crisis time. The study results provide an understanding of the strategy for employees and customers, as well as the challenges for SMEs, hotels, and their staff from COVID-19 incidents.

The findings of the thematic analysis mention the apparent difference in the strategies. Results show that the strategies of the hotels vary from country to country in developed and developing countries. A developed country, Austria, mentioned the suitable approach by all means and in every possible way, but the strategy is not similar in the developing countries. Hotel show planning for employees in Austria. However, in Pakistan and Indonesia, there was a problem in the proper implementation of the strategies. Furthermore, it shows that hotels agree to bear the cost of safety precautions and implement cleaning procedures and necessary safety measures. Further research ensures the importance of these safety precautions, measures that influence customers' attitudes and behaviors, and whether customers are willing to pay for them. Hotels and restaurants believe that applications of emerging technologies and different software can ease the business in the service delivery during the COVID-19 situation, and it is necessary to develop an environment to reduce physical contact.

Practical implications are provided from this study for the hotels, employees, visitors, travelers, governments, and other associated stakeholders. Hotels should adopt technical tools like service robots, introduce contactless payment such as apply pay or contactless bank cards, digital menus that can be viewed on personal mobile devices via QR codes, contactless digital payments, keyless entry, touchless elevators, and other facilities. Furthermore, the hotels must provide free COVID-19 tests for the staff, customers, and suspected people. In this regard, the government should support the hotels. 


\section{Acknowledgement}

The authors acknowledge the cooperation of the SME Hotels, and employees for the support. The authors are thankful to the SME hotels and the staff to cooperate and coordinate in the data collection process and facilitate the cause.

\section{References}

Bögenhold, D., \& Fachinger, U. (2007). Micro-firms and The Margins of Entrepreneurship: The Restructuring of The Labour Market. The International Journal of Entrepreneurship and Innovation, 8(4), 281-292.

Bögenhold, D., Yorga Permana, F. N., \& Popovic, K. (2021). Consumption, Middle Class and Youth. In: Knapp, G., \& Krall, H. (eds). Youth Cultures in a Globalized World: Developments, Analyses and Perspectives, 245-256.

Braun, V., \& Clarke, V. (2021). To Saturate or Not to Saturate? Questioning Data Saturation as a Useful Concept for Thematic Analysis and Sample-Size Rationales. Qualitative Research in Sport, Exercise and Health, 13(2), 201-216.

Filimonau, V., Derqui, B., \& Matute, J. (2020). The COVID-19 Pandemic and Organisational Commitment of Senior Hotel Managers. International Journal of Hospitality Management, 91, 102659. https://doi.org/10.1016/j.ijhm.2020.102659

Fofana, F., Bazeley, P., \& Regnault, A. (2020). Applying a Mixed Methods Design to Test Saturation for Qualitative Data in Health Outcomes Research. PloS one, 15(6), e0234898.

Guest, G., Namey, E., \& Chen, M. (2020). A Simple Method to Assess and Report Thematic Saturation in Qualitative Research. PLoS One, 15(5), e0232076.

Haddad, M. I., Williams, I. A., Hammoud, M. S., \& Dwyer, R. J. (2019). Strategies for Implementing Innovation in Small and Medium-sized Enterprises. World Journal of Entrepreneurship, Management and Sustainable Development, 16(1), 12-29. https:// doi.org/10.1108/WJEMSD-05-2019-0032

Hao, F., Xiao, Q., \& Chon, K. (2020). COVID-19 and China's Hotel Industry: Impacts, a Disaster Management Framework, and Post-Pandemic Agenda. International Journal of Hospitality Management, 90, 102636.

Hisrich, R. D., \& Soltanifar, M. (2021). Unleashing the Creativity of Entrepreneurs with Digital Technologies. In: Soltanifar, M., \& Hugher, M., \& Göcke, L. (eds). Digital Entrepreneurship. Future of Business and Finance (pp. 23-49). Springer, Cham.

Hung, K. K. C., Mark, C. K. M., Yeung, M. P. S., Chan, E. Y. Y., \& Graham, C. A. (2018). The Role of The Hotel Industry in The Response to Emerging Epidemics: A Case Study of SARS in 2003 and H1N1 Swine Flu in 2009 in Hong Kong. Globalization and Health, 14(1), 1-8. https://doi.org/10.1186/s12992-018-0438-6

Inyang, B. J. (2013). Defining The Role Engagement of Small and Medium-sized Enterprises (SMEs) in Corporate Social Responsibility (CSR). International Business Research, 6(5), 123-132.

Jiang, Y., \& Wen, J. (2020). Effects of COVID-19 on Hotel Marketing and Management: 
a Perspective Article. International Journal of Contemporary Hospitality Management, 32(8), 2563-2573. https://doi.org/10.1108/IJCHM-03-2020-0237

Jones, P., \& Comfort, D. (2020). The COVID-19 Crisis and Sustainability in The Hospitality Industry. International Journal of Contemporary Hospitality Management, 32(10), 3037-3050. https://doi.org/10.1108/IJCHM-04-2020-0357

Kim, S. S., Kim, J., Badu-Baiden, F., Giroux, M., \& Choi, Y. (2021). Preference for Robot Service or Human Service in Hotels? Impacts of the COVID-19 Pandemic. International Journal of Hospitality Management, 93, 102795.

Knight, D. W., Xiong, L., Lan, W., \& Gong, J. (2020). Impact of COVID-19: Research Note on Tourism and Hospitality Sectors in The Epicenter of Wuhan and Hubei Province, China. International Journal of Contemporary Hospitality Management, 32(12), 3705-3719. https://doi.org/10.1108/IJCHM-04-2020-0278

Kour, P., Jasrotia, A., \& Gupta, S. (2020). COVID-19: A Pandemic to Tourism GuestHost Relationship in India. International Journal of Tourism Cities, (In-press). https:// doi.org/10.1108/IJTC-06-2020-0131

Neirotti, P., Raguseo, E., \& Paolucci, E. (2018). How SMEs Develop ICT-Based Capabilities in Response to Their Environment: Past Evidence and Implications for The Uptake of The New ICT Paradigm. Journal of Enterprise Information Management, 31(1), 10-37. https://doi.org/10.1108/JEIM-09-2016-0158

Odoom, R., Mensah, P., \& Asamoah, G. (2017). Branding Efforts and SME Performance - An Empirical Investigation of Variations Across Firm Sizes and Business Sectors. Journal of Research in Marketing and Entrepreneurship, 19(1), 59-76. https://doi. org/10.1108/JRME-06-2016-0017.

Pett, T. L., Errami, Y., \& Sié, L. (2019). How Smaller Firms Can Outperform Their Peers. Journal of Business Strategy, 40(2), 42-49. https://doi.org/10.1108/JBS-12-2017-0178.

Rahimizhian, S., \& Irani, F. (2020). Contactless Hospitality in a Post-COVID-19 World. International Hospitality Review, (In-press). https://doi.org/10.1108/IHR-08-2020-0041

Rowley, J. (2012). Conducting Research Interviews. Management Research Review, 35(3/4), 260-271.

Schismenos, S., Smith, A. A., Stevens, G. J., \& Emmanouloudis, D. (2020). Failure to Lead on COVID-19: What Went Wrong with The United States? International Journal of Public Leadership, (In-press). https://doi.org/10.1108/ijpl-08-2020-0079.

Serrasqueiro, Z., \& Nunes, P. M. (2014). Financing Behaviour of Portuguese SMEs in Hotel Industry. International Journal of Hospitality Management, 43, 98-107.

Tavory, I. (2020). Interviews and Inference: Making Sense of Interview Data in Qualitative Research. Qualitative Sociology, 43(4), 449-465.

Wen, J., Kozak, M., Yang, S., \& Liu, F. (2020). COVID-19: Potential Effects on Chinese Citizens' Lifestyle and Travel. Tourism Review, 76(1), 74-87. https://doi. org/10.1108/TR-03-2020-0110.

Yun, J. H. J., Jung, W. Y., \& Yang, J. H. (2015). Knowledge Strategy and Business Model Conditions for Sustainable Growth of SMEs. Journal of Science and Technology Policy Management, 6(3), 246-262. https://doi.org/10.1108/JSTPM-01-2015-0002. 